\title{
A new method for recording mastication during eating and ruminating in sheep
}

\author{
P. Nørgaard ${ }^{1}$ and K. Hilden ${ }^{2}$ \\ ${ }^{1}$ Department of Animal and Veterinary Basic Sciences, \\ ${ }^{2}$ Department of Natural Sciences, \\ The Royal Veterinary and Agricultural University \\ Bülowsvej 13, DK-1870 Frederiksberg, Denmark
}

\begin{abstract}
A new method for recording jaw movements (JM) oscillations (JMO) in sheep is described. The principle used to record JMO is the changing position of the magnetic field from a magnet relative to a small Hall sensor, when both were positioned in a soft tube surrounding the mouth. The signal was sampled at $20 \mathrm{~Hz}$ by a logger hanged in a wheel joint allowing the sheep to move around freely in a small pen. The individual JM were identified and clustered into cycles. Recorded JMO, JM and cycles are presented from an ewe eating and ruminating grass silage.
\end{abstract}

KEY WORDS: chewing logger, jaw movement oscillations, rate of jaw movements

\section{INTRODUCTION}

Ruminants spent daily 3-8 h eating and 4-10 h ruminating. The rate (CR) of jaw movements $(\mathrm{JM})$ during mastication at eating and ruminating ranges from 1.6 to $3 \mathrm{~Hz}$ in sheep. JM oscillations (JMO) during eating and ruminating were recorded by different methods like simple watching of the act, by recording the sound generated from mastication. JMO were recorded by measuring the pressure oscillations in a water filled tube around the mouth (Schleisner et al., 1999), by an on off shift transducer positioned close to the skin of the mouth (Sudweeks et al., 1979; Beauchemin et al., 1989) or by recording the variable conductance in a tube close to the mouth (Rutter et al., 1997). The general tight contact of these kinds of equipments with the skin easily expose a high risk of damage on the skin after few recording days due to 100 thousands of JMO daily in small ruminants. The lack

\footnotetext{
${ }^{1}$ Corresponding author: e-mail: PEN@kvl.dk
} 
of free movement conditions or effect from the chewing halter may have negative effect on animal welfare and intake. The intended aim of the described chewing recording system was to perform a continuously recording of JMO, a minimum of technical survey, allowing the ewe to move freely in a pen and make a minimal effect on eating and ruminating behaviour.

\section{MATERIAL AND METHODS}

JMO were recorded by a Hall sensor placed in a distance of $3 \mathrm{~mm}$ from a $3 \mathrm{~mm} \times$ $3 \mathrm{~mm} \times 5 \mathrm{~mm}$ permanent magnet inside a flexible latex tube. The tube was located on the top of the bridge of the nose inside a cylindrical elastic soft cloth pocket, which surrounded the mouth of the sheep. The cloth pocket was kept in position by an elastic band behind the nape of the neck like a halter. The signal from the Hall sensor was transmitted by a $1.5 \mathrm{~m}$ electric wire inside a flexible cylindrical metal tube to the logger hooked to the roof in a wheel joint $1 \mathrm{~m}$ above the sheep. The metal tube was fixated by an elastic band allowing the sheep to move around freely in the $2 \times 2 \mathrm{~m}$ pen. The function of the recording system was demonstrated on a Shropshire ewe nursing two lambs. The ewe was fed grass silage ad libitum supplemented with $1 / 2 \mathrm{~kg}$ commercial concentrates 2 times daily. The digitised signal (DVT) was sampled at $20 \mathrm{~Hz}$. A second-degree polynomial regression of 5 continuous DVT values was used to identify local minimum (DVT_min), local maximum (DVT_max) and further the individual JM. The amplitude values (AMP) of the identified JM were calculated as the difference between DVT( $\left.\mathrm{T}_{\max }\right)$ and $\operatorname{DVT}\left(\mathrm{T}_{\min }\right)$, and the time interval (DT) between two subsequent JM is calculated from the corresponding $\mathrm{T}_{\text {max }}$ values. The individual rate (CR) of a JMO was estimated by using on sinus and co sinus relationships by assuming a JMO to proceed like a harmonic oscillation. The identified JM was clustered into eating and ruminating cycles using the principles described by Schleisner et al. (1999). The most frequent time interval (Ga_DT) between $\mathrm{T}_{\max }$ values within cycles was calculated from a gamma distribution and the basic chewing rate within cycles was estimated as $1 / \mathrm{Ga}$ DT by use of SAS version 8.1.

\section{RESULTS}

Figure 1 shows recorded DVT oscillations sampled during a section of a rumination period. The section includes the last $10 \mathrm{sec}$ of mastication on a bolus before swallowing, five sec intercycle time until regurgitation of next bolus and followed by $5 \mathrm{sec}$ continued mastication of the new bolus. The sampled DVT values oscillate around the zero line between -50 to +50 compared to a harmonic oscillation. The 29 identified DVT_max and DVT_min values represent in pair the individual JM. The 20 sampled DVT values per second make 10 DVT values per 


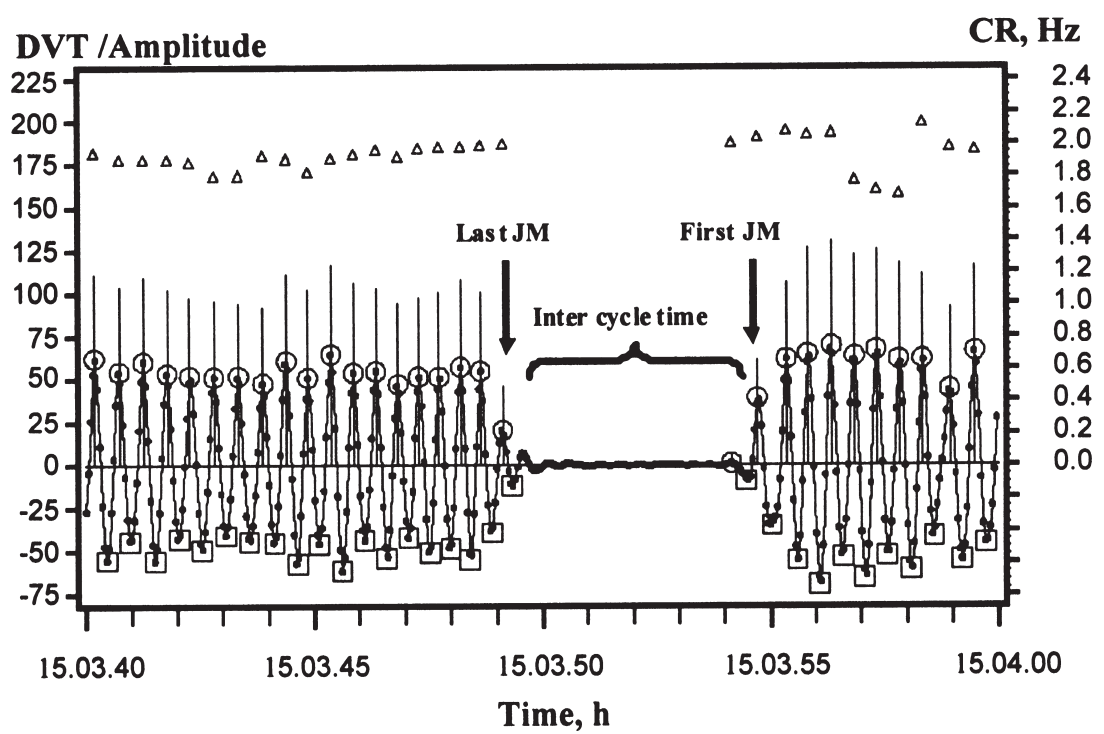

Figure 1. Connected DVT $(\bullet)$ values, identified DVT_max (o), DVT_min ( $\square$ ), rate of DVT oscillation $(\mathrm{CR})(\Delta)$ and amplitude of the individual $\mathrm{JM}(\mid)$ during 20 seconds of a rumination period shown in Figure 2

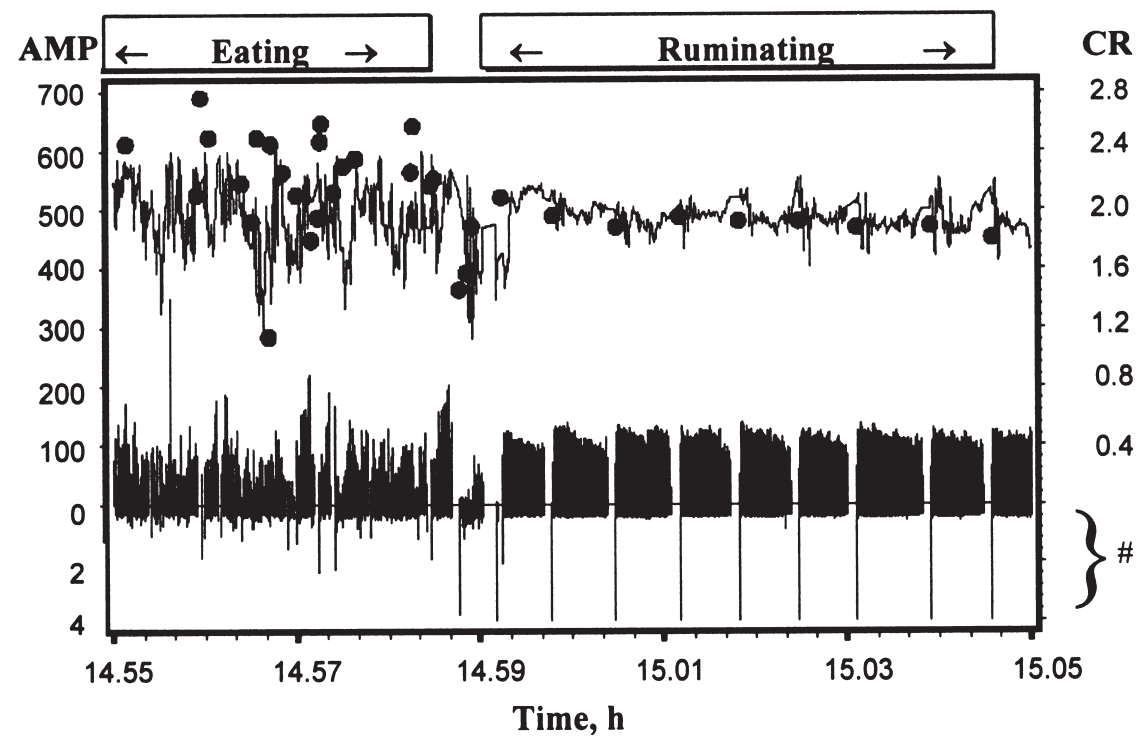

Figure 2. Upwards pointed amplitude of JM ( | ) (AMP), \# downwards pointed the time interval (DT) (sec) between JM ( $\mid$ ), rate of JMO (CR) ( $\square$ ) and basic chewing rate (•) within eating and ruminating cycles 
$\mathrm{JM}$ oscillation at a frequency of $\mathrm{JM}$ of $2 \mathrm{~Hz}$ as illustrated in Figure 1. Both the AMP and the CR values of the identified JM appear to be relatively constant during this short cut of a rumination period. Figure 2 shows the AMP, DT, and CR values during the last $10 \mathrm{~min}$ of an eating period followed by $2 \mathrm{~min}$ idling and ending with $5 \mathrm{~min}$ of a ruminating period. The ruminating period starting at $15.00 \mathrm{~h}$ includes a short section from 15.03.40 to 15.04.00 h shown in Figure 1. The size of AMP values are illustrated as needles turning upwards, whereas the length of the time interval between the individual JM (DT) is illustrated as needles turning downwards ranging from 0.3 to more than $4 \mathrm{sec}$ during the ruminating period. The AMP, DT, $\mathrm{CR}$ and the basic chewing rates within cycle values are on a quite constant level compared with the values recorded during the last $8 \mathrm{~min}$ of the eating period. The ewes masticated with a basic rate of $2 \mathrm{~Hz}$ during the ruminating period and around $2.4 \mathrm{~Hz}$ during the late part of the eating period. These values are twice the values reported by Schleisner et al. (1999) during ruminating and eating in cattle.

\section{DISCUSSION}

The chewing recorder was tested continuously during $96 \mathrm{~h}$ on 25 ewes in late pregnancy, on 35 nursing ewes and on 20 growing lamb.

\section{CONCLUSIONS}

The described chewing logger appears to have the capacity for a gentle recording of time; amplitude and frequency of JM in louse penned sheep and lamb without affecting the animal.

\section{REFERENCES}

Beachemin K.A., Zelin S., Genner D., Buchanan-Smith J.G., 1989. An automatic system for quantification of eating and rumination activities of dairy cattle housed in stall. J. Dairy Sci. 72, 2747-2759

Rutter S.M., Champion R.A., Penning P.D. 1997., An automatic system to record foraging behaviour in free-ranging ruminants. Appl. Animal Behav. Sci. 54, 185-195

Schleisner C., Nørgaard P., Hansen H.H., 1999. Discriminant analysis of pattern of jaw movement during rumination and eating in a cow. Acta Agric. Scand., Sect. A, Anim. Sci. 49, 251-259

Sudweeks E.M., Law S.E., Ely L.O., McCullough M.E., Sisk L.R., 1979. Development and application of a roughage value index for formulating dairy rations. Research Bulletin, Agricultural Experiment Stations, University of Georgia, 238, pp. 21 